\title{
Ritos de masculinidad: la construcción cultural de los hombres ibéricos en lo festivo y en el ocio
}

\author{
Rites of Manhood: the Cultural Construction of Iberian Men in \\ Festivity and Leisure
}

Joan Sanfélix Albelda

Universitat Jaume I

\begin{abstract}
RESUMEN
El siguiente artículo es una reflexión sobre la relación entre masculinidad, como construcción social, y ritualidad. Como han demostrado muchos autores durante las últimas décadas, son muchos los ejemplos en el contexto de la Península Ibérica donde podemos descubrir cómo, incluso en la actualidad, es posible encontrar algunas prácticas sociales que implican la demostración de masculinidad a través de formas rituales. Algunas de ellas están realmente formalizadas, mientras que otras tienen un nivel mínimo de institucionalización, pero en cualquier caso, en todos ellas podemos observar cómo la masculinidad, en sus valores tradicionales, requiere ser demostrada en contextos sociocomunitarios. El artículo se centra con especial interés en la relación entre rituales festivos y masculinidad, destacando el caso de "los quintos", fiesta tradicional en diferentes pueblos ibéricos, donde podemos ver rituales de masculinidad realmente bien estructurados y con una profunda conexión con los valores comunitarios-tradicionales.
\end{abstract}

PALABRAS CLAVE: masculinidad, rituales, quintos, prácticas de masculinidad 


\section{ABSTRACT}

The next paper is a reflection about the relationship between masculinity, as a social construction, and rituality. As many authors have showed during last decades, there are many examples in the context of Iberian Peninsula where we can find out how, even nowadays, it is possible to find some social practices that involve the demonstration of masculinity through ritual forms. Some of them are really formalised, while other has a minimum level of institutionalization, but in any case, in all of them we can observe how masculinity, in their traditional values, is required to be demonstrated in sociocommunitarian contexts. The article is focused with particular interest in the relation between festivity rituals and masculinity, pointing out the case of "los quintos", a traditional festivity in different Iberian villages, where we can see rituals of manhood really well structured and with a deep connection with de communitarian-traditional values.

KEY WORDS: masculinity, rituals, quintos, masculinity practices

\section{INTRODUCCIÓN}

El abordaje de la identidad masculina desde una perspectiva de género (entendido este constructo como una categoría de análisis crítica de los fenómenos sociales e históricos) que se está desarrollando desde hace una pocas décadas en el ámbito académico (Connell 1995; Fernández-Llebrez 2004; Martín 2007), ha puesto de manifiesto en diversas ocasiones que la masculinidad no solo se trata de una construcción social y por tanto resulta cambiante, sino que además es una identidad (impuesta por las lógicas patriarcales) que demanda de ser demostrada, que reclama de cierta performance en su despliegue (Gutmann 1997; Sanfélix 2017).

Es en este contexto del abordaje de la masculinidad como fenómeno occidental problematizado (Vendrell 2002) y exportado al análisis de otras culturas por la antropología y otras ciencias sociales, donde el tema de la ritualidad ha cobrado especial interés, dada la existencia de formas rituales "exóticas" que a ojos de los occidentales pueden entenderse como rituales "de masculinidad". 
El paralelismo parece inevitable a pesar de formas de organización tan dispares entre las diferentes culturas del globo. En este sentido, la localización de ritos vinculados a la conversión social de los chicos/niños (cuerpos biológicos significados culturalmente como varones) en hombres para la gran mayoría de culturas descritas por la propia antropología, genera ciertos interrogantes sobre la cuestión, a veces de tinte más esencialista, a veces desde una lógica más socioantropológica.

De hecho, en nuestro ámbito cultural, han existido y existen todavía formas rituales que siguiendo con mayor o menor ortodoxia las fases y características propias de las lógicas de los ritos de paso definidos por Victor Turner ([1969] 1991) y Arnold Van Gennep ([1909] 2013) continúan representando, al menos desde la interpretación que se presenta en este artículo, la existencia objetiva de espacios productores y reproductores de masculinidad en su versión tradicional.

Desde ritualizaciones muy estructuradas y alargadas en el tiempo, ciertamente institucionalizadas, hasta prácticas ritualizadas más fluidas e incluso imperceptibles socialmente pero efectivas en su acción-efecto, la masculinidad, a lo largo y ancho del planeta parece necesitar ser demostrada (Sanfélix 2017; Sanfélix y Téllez 2017) en el espacio del reconocimiento público que valora, e incluso venera, los valores asignados culturalmente a la masculinidad, concebida esta como esencia última de lo social y garante de su supervivencia y reproducción.

Es por tanto pertinente cuestionarse sobre determinadas realidades que derivan de un hecho que desde ciertos enfoques científicos se puede dar por contrastado: los hombres son construidos culturalmente a través de dispositivos socioculturales. El rito de paso o otras formas ritualizadas van a cobrar especial relevancia para ello, lo que denota como para la masculinidad nunca es suficiente el sustrato biológico significado socialmente. Todo esto obliga a preguntarse el porqué de esta aparente necesidad que además a día de hoy parece no tener demasiado sentido, especialmente para nuestro ámbito cultural donde las lógicas de género han cambiado sustancialmente situando a los varones en una posición compleja donde su masculinidad parece estar obsoleta (Subirats 2013).

Así pues, en este texto se abordarán algunas descripciones etnográficas sobre diferentes formas rituales no occidentales que proporcionan una información muy interesante, para después volver sobre lo occidental y concretamente el ámbito cultural español-ibérico, donde ancladas a la tradición festiva se encuentran ciertas formas rituales que hasta no hace tanto o incluso todavía hoy, permiten escenificar una performance de masculinidad que sirve en la 
reproducción y reconocimiento de los valores propios de un modelo de masculinidad tradicional. Además, se referirán finalmente algunos otros espacios ritualizados de masculinidad más relacionados con el ámbito del ocio.

\section{OBJETIVOS Y METODOLOGÍA}

El objetivo central de este artículo es poner de relieve la existencia de formas ritualizadas de masculinidad, que, todavía a día de hoy existen y se despliegan en tanto que prácticas sociales para demostrar la exigida hombría.

Concretamente, existen y se pueden contrastar diferentes espacios en lo festivo y en el mundo del ocio, entendido este último en un sentido amplio, donde diferentes performances de masculinidad son desarrolladas, más allá de sus grados de formalización y la consciencia de los actores que las despliegan e incluso las observan.

Este texto se focalizará primeramente en el análisis de la ritualidad masculina vinculada al ámbito tradicional-festivo a través de la figura de "los quintos". En segundo lugar, fijará su mirada en ciertas formas ritualizadas (pos)modernas, que emergen en espacios más fluidos, erráticos y casi compulsivos donde funcionan las lógicas de las disposiciones creadas socialmente que se ocultan en las profundidades de los esquemas del habitus (Córdova 2003; Gutiérrez 2004; Bourdieu 2007, 2008).

Por tanto, como objetivos específicos se pueden derivar los dos que se proponen a continuación:

- Determinar la existencia de prácticas ritualizadas de masculinidad que perviven (o han pervivido) en la tradición festiva popular con ciertos niveles de institucionalización.

- Reflexionar sobre la creación ad hoc de prácticas ritualizadas, con mayor o menor grado de formalización, que, en su lógica interna responden a mecanismos de construcción, reproducción y validación de la masculinidad en ciertos espacios del ocio.

Desde un punto de vista metodológico, el primer objetivo será analizado a partir de una revisión bibliográfica comparativa entre diferentes ritualizaciones de masculinidad en las festividades de los quintos en diversos pueblos españoles. En relación con las prácticas que se pueden situar más certeramente en la esfera del ocio, su análisis es fruto del trabajo de campo realizado para una investigación 
desarrollada en algunas comarcas del este peninsular entre los años 2015 y 2017 aproximadamente. Específicamente, algunas de las reflexiones y análisis que se presentarán en esta línea fueron generadas a través de la aplicación de diferentes técnicas de investigación socioantropológica tales como las entrevistas biográficas o la observación sistemática ${ }^{1}$ (Sanfélix y Téllez 2014; Sanfélix 2017).

\section{RITOS DE PASO Y RITOS DE MASCULINIDAD}

Aunque es bien conocido en el ámbito de las ciencias sociales y, particularmente en el mundo de la antropología, es necesario, no obstante, recuperar algunas ideas vinculadas con los ritos de paso conceptualizados por parte de dos autores fundamentales en esta materia; Victor Turner ([1969]1991) y Arnold Van Gennep ([1909] 2013).

Este último, en su teorización clásica sobre este tipo de estructuración de muchos fenómenos sociales, es ampliamente conocido por diseccionar los ritos de paso en tres fases que se corresponden con los denominados ritos de separación, de margen y de agregación (2013: 32). No obstante, estas fases también son estructuradas alrededor del concepto de liminalidad, idea que por otra parte y como se verá, parcialmente genera un espacio potente para la comprensión de lo humano en dimensiones concretas. Se habla, por tanto, de lo preliminar, lo liminal y lo postliminal.

Siguiendo en esta línea, es Victor Turner (1991) quien va a desarrollar una noción ciertamente interesante sobre lo liminal y que él va a concebir como communitas.

Como el propio autor destaca, lo interesante de este tipo de fenómenos liminales es cómo ofrecen un espacio caracterizado por la humildad, la sacralidad, la homogeneidad y la camaradería, entre otros aspectos. Un "momento dentro y fuera del tiempo" como apunta Turner. Se trata de la existencia contrapuesta de dos "modelos" principales de interrelación humana, yuxtapuestos y alternos. En

\footnotetext{
${ }^{1}$ Un desarrollo más exhaustivo de la cuestión metodológica se puede encontrar en los textos Sanfélix y Téllez 2014 y Sanfélix 2017. No es la pretensión de este artículo entrar en profundidad al análisis de la cuestión metodológica. Simplemente apuntar la complementariedad entre los discursos producidos en las entrevistas biográficas (dentro del método biográfico una especie de relatos de vida) y la observación sistemática (con una finalidad concreta determinada por el tema objeto de estudio y que se da de manera repetitiva pero puntual), lo que facilita una mirada más poliédrica sobre la masculinidad y sus ritualizaciones en un ámbito cultural acotado.
} 
primer lugar, la sociedad como sistema estructurado de posiciones jerárquicas. En el segundo caso, emerge de manera reconocible una especie de comunidad desestructurada o rudimentariamente estructurada y en cierta medida indiferenciada, "comunión de individuos iguales" que se someten conjuntamente a la autoridad general de los ritos. Este antropólogo apuesta por el término "communitas" en oposición a "comunidad" para distinguir estas formas de relación-estructuración social, yendo más allá de la "simple" diferencia entre lo secular y lo sagrado, entre la política y la religión (Turner 1991: 96).

A modo de resumen, desde la teorización de Turner, se desprenden toda una serie de lógicas binarias que ayudan en la contextualización de esas formas sociales divergentes, en otros términos, las diferencias entre el sistema social normalizado-jerarquizado y la liminalidad de la communitas.

En relación con esta última, destacan aspectos como el estado de transición, la homogeneidad, la igualdad, el anonimato, la ausencia de distinciones en la forma de vestir e incluso de estatus, la humildad, lo sagrado, la obediencia total, el silencio, o algunas otras ideas como las referencias a los poderes místicos (que se podrían entender como sociales desde lo analítico), la heteronomía, e incluso la suspensión temporal de los derechos y obligaciones de parentesco o la aceptación de ciertas formas de dolor y sufrimiento.

La antropóloga Mary Douglas (citada en Segalen 2014: 58) apunta en relación con esta cuestión algunas concreciones que ya se refieren al caso específico de los ritos de masculinidad. En palabras de esta autora, el peligro reside en los momentos de la transición, puesto que la liminalidad "no es un estado ni otro", sino que más bien ese es punto intermedio donde emerge el riesgo para el sujeto pero también para el resto de la comunidad. Poner en riesgo la vida de los chicos significa justamente que al salir de la sociedad y entrar en lo liminal se exponen a una situación (de poder) que puede incluso matarlos, aunque fundamentalmente, pretende convertirlos en hombres.

En esta línea ya directamente emparentada con lo que podemos entender como ritos de masculinidad, se encuentran en la antropología dos referentes muy interesantes en los autores Gilbert Herdt $(1982,1987)$ y Maurice Godelier ([1982] 2005). La filósofa e historiadora Elisabeth Badinter (1993) resume gráficamente en su conocido libro sobre la identidad masculina algunos aspectos de los abordados por estos autores. Por ejemplo, cuando se adentra en la cuestión de los sambia en Nueva Guinea, destaca la figura de la flauta anunciadora del principio de la iniciación de los chicos. Estos son arrebatados del mundo femenino (sus madres) y son llevados a los bosques. Una vez allí y durante tres 
días van a ser víctimas de todo un proceso ritual que tiene que ver con el dolor y el sufrimiento: azotes, provocación de hemorragias nasales para purgar "líquidos femeninos", etc., hasta que finalmente y en el último día se les revela el secreto de las flautas que no pueden descubrir a las mujeres (1993:102).

Esta misma autora señala como esta práctica de arrancar a los niños de sus madres y separarlos dejándolos en un lugar desconocido durante un tiempo determinado, es una cuestión relativamente recurrente en algunas culturas. Apunta cómo, sin comida, sin bebida y en medio de la nada se constituye esa aparentemente y culturalmente necesaria fase liminal que los conduce en ocasiones a un estado de shock.

Rita Segato (2003), la antropóloga argentina, aborda la lógica secreta de las flautas, cuestión, esta del secreto, intensamente relacionada con el poder masculino. Como esta profesora describe y recuperando las aportaciones del citado Maurice Godelier (2005) la ritualidad que se despliega desde lo simbólico de la flauta esconde en realidad que esta fue robada a las mujeres, beneficiándose por tanto los mismos varones ahora de su uso. Todas estas cuestiones forman parte de una lógica compleja donde se demuestra que masculinidad se sustenta sobre estructuras frágiles que tienen mucho que ver con la violencia contra las mujeres (Segato 2003: 16). Sin embargo, la violencia de estos rituales no va a ser unidireccional, sino que como se está señalando, también va a tener como destinatarios a los propios chicos, quienes posteriormente accederán al espacio masculino del poder y del privilegio, aunque previamente hayan pagado un peaje que, en todo caso, parece merecer la pena (tampoco parece haber alternativa).

Otra figura muy interesante y ampliamente conocida en la literatura antropológica es la que describe Margaret Mead ([1935] 2014) en relación con los ritos de masculinidad de los niños arapesh. Se trata del "tamberan" una ser "sobrenatural" que es imaginado por los propios niños como un monstruo gigantesco que viene desde los mares y que es anunciado a través del sonido de unas flautas.

De igual forma que en otras iniciaciones, las lógicas subyacentes al propio ritual se estructuran en la separación de lo femenino (el mundo de las madres) y la emergencia de aspectos vinculados con lo sagrado o lo trascendente y místico; cuerpos, prohibiciones, alimentos que no deben ser tocados, incisiones sobre los cuerpos, etc., que van a estar presentes articulando la lógica ritual que se reviste de poder simbólico efectivo para performativamente transformar a los chicos arapesh en hombres adultos. 
Sin entrar en profundidad a una mayor revisión antropológica sobre los rituales de masculinidad, sirva esta pequeña muestra para incidir en dos ideas: la masculinidad se ritualiza en la gran mayoría de las culturas conocidas y en muchas de ellas implica formas explícitas de violencia contra los neófitos.

\section{LOS QUINTOS: UN RITUAL DE MASCULINIDAD}

Centrando ya la mirada en el ámbito occidental y concretamente ibérico, se relatan a continuación una serie de ejemplos situados en diferentes localidades a lo largo y ancho de la península que van a ayudar a visibilizar el nexo entre la ritualidad festiva y la masculinidad a través de "los quintos".

Asociado históricamente a lo militar y al servicio al rey, perduran todavía en nuestro ámbito cultural unas fiestas que se esparcen por la geografía ibérica y que tienen mucho que ver con lo masculino en su versión tradicional.

La festividad de los quintos, con su particular recorrido histórico, que particularmente aquí no se abordará, refleja bastante fielmente y especialmente en algunos casos, la importancia de la lógica ritual para la masculinidad. De hecho, desde una lectura del género como construcción sociohistórica y atendiendo a la masculinidad como una identidad forjada por lo patriarcal y que reclama de ser demostrada, es bien conocido en el ámbito de la antropología como históricamente las sociedades han creado mecanismos culturales para que los candidatos a "hombres de verdad" pudieran demostrar frente a propios y ajenas (en lectura binaria de los sexos) su validez para el puesto. En otros términos, y más allá de marcadores cronosociales claros para biografías menos líquidas que las actuales y vinculados con la adultez, pero a la par confirmadores de lo esperado para los varones, han existido y la pregunta es si todavía existen, formas rituales de masculinidad que tratan de dar respuesta a una demanda social (quizás cada vez menos manifiesta y en gran parte no consciente) sobre la exhibición y performance pública de la hombría, en este sentido, hombría caracterizada por la fragilidad, puesto que nunca es suficiente desde su sustrato supuestamente biológico, sino que reclama expresamente de intervenciones socioculturales sobre cuerpos significados.

Por tanto, y como se ha visto en otras culturas no occidentales, es bastante frecuente encontrar ritos que podríamos denominar de masculinidad a lo largo y ancho de nuestro ámbito cultural. En el caso español, si bien la mili (el servicio militar obligatorio) es un ejemplo claro (puede que sea el que establezca un paralelismo más claro con los ritos "exóticos" de masculinidad -aun en sociedades 
industriales- por su pureza trifásica), la fiesta de los quintos, que podría entenderse como el final de la fase preliminar (en relación con la mili), la preparación para la entrada en el umbral, tiene, a la vez, también sus lógicas tripartitas, aunque no siempre claramente tan marcadas como en el caso de esta institución de lo bélico.

Un breve recorrido desde lo bibliográfico nos da cuenta de cómo una pequeña selección del amplio abanico de posibilidades de este tipo de ritualidad festiva, puede ofrecer una idea clara de cómo todavía perviven, o al menos lo han hecho hasta no hace demasiado, ciertas lógicas y códigos propios de un modelo tradicional de masculinidad que se sujeta en el pasado para perpetuarse y reproducirse simbólicamente en el presente, pese a estar en tiempos que bien podríamos convenir como del feminismo, y lo hacen precisamente a través de lo festivo.

Entrando ya en el tema de la ritualización de lo masculino en el ámbito españolibérico, puesto que se referenciará también un caso portugués en perspectiva comparada, se pueden localizar espacios de lo festivo que trascienden las lógicas propias de nuestro momento histórico, es decir, del capitalismo postindustrial, de la modernidad líquida, del proceso de individuación, etc., que apelan directamente a la sociabilidad festiva comunitaria, anclaje de valores tradicionales en muchas ocasiones y engranaje para la reproducción, o mejor dicho, para la veneración-exaltación, reconocimiento y legitimación de una masculinidad, quizás a estas horas en proceso de obsolescencia (Subirats 2013).

En este breve recorrido por ejemplos de los quintos como ritualidad masculina, a continuación se analiza en primer lugar el caso del pueblo de Navalosa en Ávila que describe certeramente Bernardo Calvo Brioso (2012). Se trata de una festividad carnavalesca, los denominados cucurrumachos; fiesta gestionada por los quintos (masculinos) aunque si bien es cierto se han incorporado recientemente las chicas, cuestión que como se irá viendo, es en cierta medida importante, para nada banal, pese a divisiones sexuadas de las funciones festivas y formas de ritualización claramente diferenciales entre los sexos.

Para comenzar, los chicos de Navalosa lo que hacen es buscar una casa o local viejo, donde traerán leña para poder calentar el espacio interior, lo que vendría a suponer el espacio físico-simbólico de la separación. En este caso del pueblo castellano, va a aparecer también una parte ritualizada de los quintos que tiene que ver con el traslado de un árbol a la plaza del pueblo, empezando por su tala y siguiendo con el transporte hasta dicho lugar. Todo ello realizado siempre de manera colectiva por ese sujeto que no es otro que una masculinidad en acción 
demostrativa de su control sobre el medio natural, su habilidad, su capacidad de gestión de lo local (aunque en este caso sea meramente festivo).

$\mathrm{El}$ autor de este texto, apunta como los quintos hacen frente a su rito de paso de niño a mozo a través de un conjunto de "pruebas" que en caso de ser superadas les van a visibilizar como hombres a ojos de la comunidad. Cuestión que como se mostrará, parece recurrente en este tipo de ritualidad.

Pedro Talaván (1989), por otra parte, describió en su momento un rito de similares características en el Valle del Ambroz en Extremadura. Este autor directamente denomina a la fiesta como "masculina y guerrera", donde van a emerger aspectos concretos vinculados con el modelo tradicional de masculinidad como la caza, la leña, el consumo de alcohol, los animales (el gallo como amo del corral y el macho cabrío, animal rebelde, que pelea y gana) etc. Sin embargo, en el caso de este lugar extremeño, llama especialmente la atención la figura ritualizada de los denominados "los pisos", práctica que primordialmente se aplica a aquellos forasteros que buscan como pareja a una de las chicas del pueblo y a los que se les va a cobrar por dicha "adquisición", lo que, sin duda, denota como los hombres simbólicamente no solo son los garantes protectores del territorio, sino que lo que está allí, incluidas mujeres, también les pertenece. De hecho, en la práctica se trata en cierto modo de poner a prueba la hombría de los candidatos a llevarse a las mujeres del pueblo, puesto que su propia dinámica implica cierta forma de violencia colectiva masculina, aunque en un tono festivo, contra el forastero:

Una muchacha se hace novia de un hombre de otro pueblo [...] A la segunda o tercera ocasión que acuda al pueblo, los quintos se acercarán a él para pedirle el piso [...] Los quintos se van juntando, y alguien grita a voz alta, “ipiso!”, “ipiso!”, responden otras voces. Aíslan al forastero de la novia y le explican en qué consiste el evento [...] Se discute la cantidad, como si fuera un trato; no consiste en que el forastero pague copas, sino en que pague una cantidad determinada de dinero, que después se gastará comunalmente. Si el forastero, cumplido el plazo que le han dado, no responde adecuadamente, los quintos le tiran al pilón, porque lo que trataba era de engañar a la muchacha... (Talavan 1989: 364)

Siguiendo con otro ejemplo localizado en latitudes peninsulares, y a pesar del tiempo transcurrido y los posibles cambios en las lógicas internas de esta celebración ritual de la masculinidad (como parece está pasando en varias de 
ellas), los quintos de Galaroza que relata Pedro Cantero (2003) son un ejemplo concreto de estas lógicas que relacionan masculinidad y ritualización en el ámbito festivo con unas fases también claramente marcadas. Según este autor, la quinta es un rito masculino a través del que se pretende afirmar la virilidad y separarse del mundo femenino. En sus propios términos, "ritual asesino" que trata de facilitar la "emergencia del hombre".

En este mismo texto se describe el proceso ritual de este pueblo de la sierra de Huelva donde encontramos elementos interesantes como la separación temporal de la sociedad normalizada (y por tanto, el acceso a lo liminal y a su pertinente espacio-tiempo communitas) y determinados actos violentos, como por ejemplo matar gallinas o batearlas.

Profundizando en este relato y sus reflexiones sobre lo ritual, la quinta, en palabras del autor, marcaba el punto de inflexión de la mocedad, preparando al joven para convertirse en hombre. Además de la libertad festiva que genera y libera el propio ritual, se refuerzan los lazos entre los chicos de la misma edad, chicos que se preparan para "retornar" a su comunidad después de la ruptura con el lazo materno, para poder de este modo enfrentar la exigencia sobre su masculinidad en su formato trabajador, guerrero, padre (2003:60).

Dentro de la lógica festiva del ritual, y más allá de algún aspecto mencionado, lo más destacable es ese paralelismo casi puro que se puede establecer con otros ritos propios de culturas que nos quedan lejanas, pese a la no existencia de elementos explícitos de violencia autoinflingida por la masculinidad (quizás se puede concebir esta diferencia como la más destacable entre los ritos no occidentales y los occidentales, aunque cabría matizar algunas cuestiones respecto a la concepción de la violencia desde el punto de vista del riesgo). Aparte de desarrollar esas actividades que exaltan valores atribuidos a la masculinidad (en su formato más tradicional), existía una fase de separación comprendida por un periodo de alrededor de diez días. Durante este tiempo de communitas se potenciaba la camaradería que la propia convivencia generaba en un contexto de consumo de vino, canto de canciones machistas, etc., rematando el ritual con el consumo de prostitución (Cantero, 2003: 60-63).

Mónica Cornejo y Chema Espada (2001), por su parte, relatan el caso de los quintos de Noblejas en Toledo. Esta autora y autor también lo conciben como un rito de paso, destacando afirmaciones en el texto como que la tradición popular festiva facilita que la misma sociedad permita a los chicos del pueblo "hacerse todo un hombre". Por supuesto, esto se intensifica desde la particularidad de la vinculación de los quintos con la ya mencionada mili. 
Entrando al detalle de la estructura ritual, destacan algunas fechas señaladas en su calendario festivo, que, sin entrar a una descripción etnográfica exhaustiva, reclamaran una vez más de los valores propios de una masculinidad tradicional. Suelen emerger en bastantes contextos rituales de los quintos, las demandas de fuerza, destreza, etc., ya sean individuales, como se verá, pero también grupales. En Noblejas, por ejemplo, arrancan varios olivos de los campos cercanos para transportarlos y disponerlos en círculo en la plaza del ayuntamiento. Una vez montado este escenario, los chicos se van al "cerco" donde pasarán la noche bebiendo y comiendo y acabando de preparar ciertos componentes simbólicos del ritual que portarán la mañana siguiente. Emerge aquí una figura ciertamente destacable, como ya se ha visto con el caso de las gallinas; en este caso se trata de un carnero al que emborracharán y maltratarán durante la noche. Como veremos, el control violento sobre la naturaleza en forma de otras especies animales, suele estar presente en ciertas formas rituales de los quintos. Elemento que casa muy bien con cierta lógica masculina vinculada con lo guerrero y la anulación de ciertas emociones.

Dentro de este texto sobre los quintos del pueblo toledano, por otra parte, resaltan especialmente algunas consideraciones generales que proporcionan el y la autora en relación con las formas ritualizadas de masculinidad. Resumiendo estas ideas, que parecen sintetizar bastante bien la dinámica ritual de los quintos en general, se destaca como estos podrían considerarse un claro ejemplo de grupo de pares masculino que se unifica en un sujeto colectivo (que por otra parte demanda de la participación de todos los varones de determinada edad) en el que se va a reafirmar determinado modelo de masculinidad relacionado con la violencia, la humillación de otros/as, el maltrato animal, la ingesta de alcohol, la potenciación de la homosocialidad heterosexual, etc. Todos estos aspectos, siguiendo con los autores, son relevantes puesto que tiene cierto componente de obligatoriedad para los chicos en edad de quinta. Destaca en este punto que, aunque no todos llevan los valores, y por ende las prácticas, a sus extremos, sin embargo los que no participan de manera tan activa igualmente permiten o dejan hacer a los otros, lo que en principio legitima esas formas de masculinidad y lo que entronca, en cierto sentido, con la lógica de la complicidad que caracteriza a la denominada por Connell, masculinidad cómplice (1995). Dejar hacer, porque lo que simboliza, genera y legitima es un sistema que me genera beneficios, aunque yo no esté a primera fila en la demostración pública de la masculinidad más bárbara. 
La mencionada Mónica Cornejo, en este caso con Ema Pires (2003), propone en un artículo muy sugerente una comparativa entre el ya mencionado Noblejas y otro pueblo del país vecino en la península, Portugal. En primer lugar, es destacable este fragmento donde se reflexiona sobre el rito de paso y de masculinidad de los quintos de Barrancos, municipio situado al sudeste lusitano.
La evolución del rito en análisis, ha sido influenciada por un conjunto de condicionantes socioeconómicos, demográficos, culturales y mentales. Los quintos son hoy un rito esencialmente performativo. En un contexto en que, frente a las presiones exteriores que la comunidad ha sufrido, la tradición es un poderoso argumento para justificar y legitimar diferencias frente a lo otro, la fiesta de los quintos tiene un carácter esencialmente codificador, performativo y reproductor del universo social y del modo en que la comunidad se imagina en cuanto tal y se proyecta endógenamente, lejos de los focos de la mediatización. Además de esta diversidad de condicionantes sobre la vitalidad del rito, un conjunto más vasto de modificaciones sociopolíticas a lo largo de estas tres décadas trajeron un universo de nuevos significados sobre qué es «ser hombre», o sobre la inspección militar como un rito de pasaje a la edad adulta. En los nuevos contextos contemporáneos, un conjunto de incertezas frente al futuro y las perspectivas profesionales $y$ educacionales, colocan la continuidad del ritual ante nuevas interrogantes y funcionalidades (2003: 188-189).

La descripción de algunas partes de la festividad de los quintos de esta localidad portuguesa, pueden resultar de interés en el sentido de esos valores que asociamos con la masculinidad (en este caso, esa rebeldía y cierta irreverencia que parece condición sine qua non para demostrar la misma durante la juventud -siendo estas actitudes reclamadas y legitimadas por la propia comunidad-).

Por ejemplo, las autoras señalan como los jóvenes recorren las calles del pueblo por la noche, montando disturbios, cantando y recorriendo los bares locales. Destacan varios aspectos en sus palabras, fundamentalmente desde determinada lógica simbólico-espacial. Como apuntan, las calles de la villa son el espacio de celebración donde los quintos se vuelven visibles como unidad autónoma dentro de la comunidad, cuestión, esta de la performance masculina en lo urbano (Delgado 2019) que resulta fundamental para comprender las lógicas contemporáneas de la masculinidad y que se puede relacionar con fenómenos históricos y actuales como los (neo)fascismos (Sanfélix 2018). 
Las autoras, en esta misma línea, inciden en cómo el comportamiento del grupo se va a caracterizar durante estos momentos del rito por un "soporte corporal y comportamental" que en cierta forma transgrede el orden de la cotidianidad, fundamentalmente por sus actitudes y prácticas diferenciales del resto de la comunidad. Especialmente destaca la referencia a la communitas en tanto que “organización autónoma dentro de la comunidad más vasta a la que pertenecen, en una ruptura con el estatuto anterior y en dirección a un futuro nuevo estatuto, el de hombre adulto" (Cornejo y Pires 2003: 87).

Por último, en relación con este ritual, se pueden resaltar algunas partes que por su carácter simbólico tienen especial relevancia. Es el caso del "velatorio", fase del ritual de los quintos portugueses donde la comunidad, en este caso las familias respectivas de los futuros soldados, "velan" por el bienestar de su hijo en el paso a un nuevo estatuto.

En la segunda parte del texto, Mónica Cornejo, como se apuntaba, recupera el relato ritual de los quintos de Noblejas. Con toda una parafernalia particular que implica figuras como los "maricones" y los "pelusos" que son generaciones de chicos vinculados por edad a los propios quintos, los días fuertes de la fiesta discurren de manera que todo cobra sentido: los chicos se van a convertir en hombres adultos a ojos de su comunidad.

\begin{abstract}
Segregados en su «cueva» y amparados por la nocturnidad, los quintos de Noblejas se recogen como iniciados para preparar la dramatización que protagonizarán. Toman las calles promoviendo tanto los disturbios como sobretodo las reacciones cómplices de quienes se van encontrando y tal vez hagan huir. Y finalmente, salen el domingo a cantar a la plaza como prueba de la superación de su noche gamberra, una noche que en realidad dura tres años, y que les proporciona la muesca simbólica de «haber sido quintos», y estar en otra etapa de su vida. (Cornejo y Pires 2003: 193)
\end{abstract}

Cerrando las menciones a este texto antropológico comparativo, son sugerentes también algunas reflexiones finales sobre la festividad y sus transformaciones en dos lugares diferenciados pero con elementos comunes. Aunque las autoras van a centrar su análisis más en esa lectura de la readaptación a tiempos modernos de las lógicas festivo-rituales de los quintos, sin embargo, huelga decir que el interés de este artículo para lo que aquí se pretende defender ya no es tanto esta sugerente perspectiva, sino una profundización en la tendencia a reproducir en lo festivo determinadas dinámicas comparables entre los pueblos ibéricos que, 
aun en la modernidad líquida contemporánea, cuando apuestan por "teatralizar" una actuación casi gamberra y desenfrenada de apropiación del espacio-tiempo local e incluso del dominio efímero sobre el orden normal de las cosas, apuesta ineludiblemente por un modelo de demostración de los valores propios de la masculinidad tradicional, aun habiendo desaparecido el elemento central y génesis de la fiesta como era el reclutamiento de los jóvenes para el servicio militar.

Esto último, como apoteosis de la masculinidad (popular) llamada a filas para defender la patria o cualquier interés de las élites dominantes de cada momento sociohistórico, como señala George Mosse, cobra especial intensificación, aunque siempre permanezca latente, durante los momentos fascistas. Por ejemplo, y como apunta este autor, el fascismo entiende lo heroico como la verdadera expresión de la masculinidad (2000: 194). Cuestión nada banal, dados los tiempos actuales.

En este viaje por la península, se encuentran también en otras regiones ejemplos de ritualizaciones de masculinidad vinculadas a los quintos. Alejandro Idáñez de Aguilar (2010) habla sobre esta festividad en la región albaceteña, concretamente en Bienservida.

En el caso concreto de Bienservida la fiesta de los Quintos constituye un raro ritual de paso o pasaje de origen no precisado, que en su desarrollo ofrece una serie de rasgos singulares que muestran su verdadera dimensión y significado, en cuya composición se observan las tres etapas que son inherentes a los actos mágicos: la Preliminar de separación, Liminar o afirmación, y Postliminar de agregación, que constituyen el esquema mediante el cual se simboliza la transformación que opera en los participantes y en la sociedad local. El ritual festivo de los mozos alistados consta por tanto de unas determinadas fases ceremoniales en que se manifiesta el acontecimiento cívico-religioso, que los jóvenes de la localidad protagonizan dentro del año en que alcanzan la edad de su llamamiento al Ejército al cumplir los 18 años, coincidiendo con la mayoría de edad legal. Los actos festivos se plasman en la conocida Fiesta de Quintos que se celebra en Semana Santa, durante la cual los quintos intervienen muy activamente en la vida del pueblo y en los actos cuaresmales religiosos y desfiles de imágenes. 
Van a emerger nuevamente elementos recurrentes, como la casa de los quintos, la figura de un animal, en este caso un carnero, o la "toma simbólica" de la plaza del pueblo. Por otra parte, también aparecerán aspectos mágicos vinculados con lo religioso, o más bien sacralizaciones de la representación religiosa que se observan en las procesiones donde solo soldados veteranos y nuevos quintos portan los pasos, excluyendo al resto de varones de dicha actividad. La masculinidad se autoinviste de poderes sacralizado-simbólicos. Desde su propia idiosincrasia, aparecen también elementos festivos y ritualizados como la denominada "quema de la bandera", acontecimiento en el que a partir de las doce de la noche del Sábado Santo los quintos veteranos de la quinta anterior, con el pertinente juego de fuego y cohetes, van a formar una torre humana para retirar la bandera de la puerta del templo "entre vivas, gritos y coplas, procediendo a quemarla en la plaza a la vista de todos" y mientras, alardean con cantos de exaltación de los quintos (Idáñez de Aguilar 2010: 317).

Para las familias el paso a la madurez del quinto va a representar un acontecimiento importante, acompañado de todo un simbolismo lleno de efemérides que en la intrahistoria familiar se conservaran como parte de su identidad; por ejemplo, las cintas que cuelgan en las fachadas de la iglesia y que guardaran finalmente en sus hogares. La misma fiesta produce una idea concreta para la comunidad local sobre la "nueva condición" que los chicos de la quinta adquieren al ser convocados para el ejército, representando esta situación un gran acontecimiento que actúa "a la manera de un gran ritual iniciático universal, significativo e impuesto por el estado" (Anta Félez, citado en Idáñez de Aguilar 2010: 320).

Recuperando las aportaciones de José Luis Anta Félez, el autor vincula de manera más clara ritual, masculinidad y lógicas simbólicas de los quintos con la mili o el ejército:

El servicio militar sirve (funciona simbólicamente) como un gran sistema de socialización, en el que los sujetos predeterminados pasan por un proceso al que se adscriben, adaptan, aceptan y asumen unas características que son condición indispensable para la adquisición de su identidad como ciudadanos-soldado; el hombre patriótico, el religioso, etc.

De esta manera puede decirse que el paso de la adolescencia a la juventud y, a su vez, de ésta a la adultez, se ritualiza con un sistema de identificación estatutaria, que permite la transmisión/adquisición de los valores culturales masculinos del hombre adulto (Anta Félez 1997: 175). 
Además, se observan también otros elementos simbólicos que van a relacionar el proceso festivo con la masculinidad. En este caso, un tapiz floral que cubre una imagen religiosa que sirve para representar la renovación primaveral del campo y las plantas y que alegóricamente representa a la nueva generación de hombres maduros que se integran con su nuevo estatuto en la comunidad "siendo portadores del don de la fecundidad como seres destinados a crear una nueva familia, refrendada por la presencia de las jóvenes en flor que les siguen en la procesión llevando las andas de San Juan" (2010: 322).

En estos últimos apuntes se observan con claridad dos cuestiones que son importantes para las reflexiones de este artículo: una visión de la masculinidad ligada a su función progenitora, una de las tres funciones de la masculinidad ubicua propuesta por el antropólogo David Gilmore (1990) junto con la protectora y la proveedora, y una participación de las chicas, que aunque se apunta en el mismo texto que cada vez lo hacen de manera más activa en la fiesta, no dejan de hacerlo desde una división simbólico-sexuada de roles, estatus $\mathrm{y}$ espacios en contextos heteronormativos.

Destaca también en la parte final de este texto una cuestión teórica importante: la aplicación de una lectura ortodoxa de los ritos de paso con sus correspondientes tres fases que se puede leer en esta fiesta.

La existencia de las tres fases del ritual se representa sucesivamente en el acto Preliminar con la quema de la Bandera anterior que representan los jóvenes de la quinta anterior; la segunda o Liminar por la celebración de la fiesta de los quintos propiamente dicha en forma de alardes, banquetes y exhibición callejera, que se realza con la exposición en el pórtico de la Iglesia de las cintas de los nuevos quintos y la instalación de la Bandera sobre la puerta de entrada al templo, donde permanecerá todo el año a la vista de los vecinos como mensaje indeleble dirigido a la comunidad, y el acto central del rapto de la imagen de Jesús Resucitado. La última fase Postliminar o de agregación, se formaliza por la reconciliación entre madre e hijo escenificada en el acto del reencuentro de la Virgen y el Resucitado, y con la adhesión a la procesión del Resucitado revestido de flores y renovado, la participación exclusiva de los quintos nuevos y veteranos en las procesiones de los pasos que toda la población acepta, y del reconocimiento público por la sociedad de la nueva condición de personas que entran en la fase de la adultez, que se hace extensiva también a las muchachas que llevan a San Juan. (Idáñez de Aguilar 2010: 324) 
Dejando ya atrás tierras albaceteñas, se fija ahora la mirada en una ritualización particularmente plástica en tierras valencianas, concretamente en la localidad de Agost, en la zona alicantina. El título del artículo sintetiza muy bien las intenciones del mismo, como se verá a continuación: "Como llegar a ser hombre con un collar de naranjas y una manta en la cabeza. Análisis de un rito de paso: los naranjeros en les dances del Rei Moro d'Agost' (Morant 2014).

Dejando de lado las particularidades de la fiesta analizada desde el punto de vista más estrictamente etnográfico, de nuevo aparecen elementos recurrentes, como la figura de los quintos, la casa de "separación", el alcohol, los animales, etc., pero sobre todo la legitimidad que tiene para el resto del pueblo sus actos, otorgándoles efímeramente la condición de cuasi "sagrados".

... los danseros y naranjeros establecen un "cuartelillo" en una casa de campo alejada del pueblo durante los siete días que duran las fiestas donde estos jóvenes comen, beben, duermen y organizan fiestas privadas. Durante este periodo de tiempo vivirán en una especie de inmunidad total donde toda la comunidad comprende y escusa cualquier actividad ilícita que pudieran realizar. Es común que acechen los campos y fincas del término municipal y roben animales, leña y todo lo que les pudiera ser de utilidad. Las madres y padres ven con relativa complacencia los abusos etílicos y otros tipos de actuaciones histriónicas. Los jóvenes iniciados están fuera de la sociedad, y la sociedad carece de todo poder sobre ellos, son considerados cuasi sagrados. (2014: 451)

Nuevamente, superar pruebas para ser reconocido como "adulto" está en la esencia simbólica del ritual. Sin embargo, esta adultez siempre se corresponde con lo heteronormativo y es propia de ciclos de vida masculinos, como bien se desprende de estas líneas donde vuelven a resonar las funciones de la masculinidad gilmorianas.

Los jóvenes iniciados que logran superar todas las pruebas contenidas en estos rituales alcanzan el derecho de ser reconocidos como adultos dentro de esta sociedad. A partir de entonces, adquieren la aprobación social para empezar una casa, formar una familia, y participar de las instituciones sociales. (2014: 451)

En definitiva, en este ritual valenciano van a emerger con fuerza aspectos de carácter ritual muy plástico relacionados con la particularidad festiva de estas comarcas, donde el fuego, la pólvora y las naranjas van a cobrar un sentido 
especial y diferenciador, pero que en el fondo todo gira sobre las lógicas de la destreza, la habilidad, la valentía y la asunción de riesgos, en la demostración de la hombría. Son en este sentido interesantes las figuras generacionales y sus funciones, que se detallan a continuación a modo de resumen de la fiesta de quintos de Agost (Morant 2014: 450).

En primer lugar, estarían los "naranjeros", de 17 años, escalón más bajo de la pirámide festiva. Son los neófitos que se caracterizan por la igualdad y la camaradería, aspectos destacados por las teorías de Turner señaladas con anterioridad. Su papel es alcanzar las naranjas que los "danseros" colgaron en la plaza la noche de los cohetes, prueba de destreza escaladora que una vez superada les otorga el derecho a organizar las fiestas del siguiente año. Tienen una especie de guarida donde conviven desde el primer día de la fiesta hasta su performance de masculinidad.

En segundo lugar, se encuentran los "danseros", de 18 años. Estos son los encargados de organizar las fiestas mayormente. Ser dansero es ser hombre, responsable, símbolo de virilidad y de madurez.

Por último, los quintos tienen 19 años y es un estatuto que se adquiere tras haber sido dansero. Desde este punto se pueden considerar ya hombres adultos y representan la experiencia, la supervisión, etc.

Todos estos grupos de edad están relacionados entre sí, son como las diferentes etapas del rito que se alargan tres años, cuestión, por cierto, que demuestra que la consecución del estatuto de hombría tiene diferentes duraciones y temporalidades en función de cómo cada comunidad local o cultura estipula los ritos y sus particulares etapas.

Para finalizar con esta ritualización masculina valenciana, y aun no compartiendo la totalidad de lo expresado en las siguientes líneas, el autor, Miguel Morant señala estas cuestiones que estarían insertas en una lectura junguiana del propio ritual, que si bien, son interesantes en algunos aspectos.

Son un ejemplo de comunión entre los nuevos rituales que emergen de un mundo global, con ritos ancestrales mantenidos generación tras generación, a modo de una celebración simbólico-ritual encargada de conectar con la psique primigenia, con lo ancestral del ser humano. Pretenden dar equilibrio emocional al sujeto, cubriendo la necesidad primaria de afiliación, desarrollando su masculinidad, construyendo su identidad por medio de la comunión entre iguales y todo ello a través de rituales preestablecidos dentro de grupos, por rangos de edad y responsabilidad. (2014: 454) 


\section{MÁS ALLÁ DE LO FESTIVO: EL OCIO COMO ESPACIO DE RITUALIZACIÓN DE MASCULINIDAD}

La exigencia de la demostración pública de la hombría toma forma en otros espacios sociales que trascienden lo festivo, aunque este locus con idiosincrasia propia despliega la posibilidad de una formalización de lo ritual en principio más elevada. Sin embargo, en sociedades aparentemente desacralizadas o con cierta tendencia a la restricción del ritual, al menos en sus formatos más ortodoxos, místicos y solemnes (aunque eso siempre va a depender de la lectura que hagamos del ritual contemporáneo), tienden a emerger otros espacios que una vez más se podrán medir en función de su grado de institucionalización o formalización y que también tienen que ver con lo ritual.

Frente a la ausencia de ritos de masculinidad claramente señalados en la biografía masculina contemporánea, por lo menos para el ámbito cultural de análisis y una vez desterrada la mili como mecanismo ritual de hombría, los chicos van a buscar espacios donde dar salida a esa necesidad de probar su valía para el puesto de "hombre de verdad" exigido todavía por la sociedad.

En el apartado anterior se ha señalado cómo en el ámbito de lo festivo, que por sí mismo ya tiene cierta imbricación con lo tradicional, se producen ritualizaciones de masculinidad a través de una figura festiva ibérica tradicional como los quintos. En estos casos, como se ha apuntado, el nivel de formalización del rito es claramente elevado e incluso comparable, con ciertos matices diferenciales ya apuntados (y para nada banales), con ritos de paso de otras culturas no occidentales, especialmente por contener tanto la lógica trifásica como de alguna manera reproducir muchos de los elementos anteriormente mencionados, particularmente en relación con la communitas que detalla Victor Turner (1991).

Puesto que este tipo de ritualidades, los quintos, no tienen un alcance ni capacidad de impregnación alto entre la población masculina del conjunto del territorio, y como además se podrían circunscribir al ámbito de lo rural (aunque quizás también cabría matizar aquí algunas cuestiones frente a determinada dicotomía excluyente entre lo urbano y lo rural para la sociedad contemporánea) los chicos, los niños, e incluso los jóvenes, frente a la no existencia clara de marcadores crono-sociales que permitan demostrar de manera fehaciente la hombría en términos clásicos y en este período sociohistórico líquido, buscan, sin duda y no necesariamente desde lo consciente, espacios donde dar salida a lo social incorporado. Una especie de pulsión de masculinidad, que utilizando la terminología antes apuntada, se esconde en las profundidades de los esquemas del habitus. 
Estas prácticas pueden darse en varios espacios, aunque particularmente se analizaran las lógicas intrínsecas de unos pocos de estos en este texto.

Particularmente se ha podido investigar como el mundo del fútbol, concretamente el futbol base, o determinados espacios del ocio, por ejemplo ciertos lugares de baño (frecuentemente prohibido) o incluso lógicas insertas en lo urbano o periurbano, como el ocio nocturno, las tribus urbanas o algunas prácticas concretas que reproducen simbólicamente lo bélico, son espacios contemporáneos donde se dan principios de ritualización de la masculinidad.

El tema del deporte, como señala Martine Segalen está intensamente vinculado a lo masculino y a lo ritual. Para esta autora existen nexos contrastables entre la hombría, lo sagrado y el deporte, este último entendido como "ritual contemporáneo". Como ella misma señala, fútbol, tauromaquia o el mundo de la caza permiten observar una dimensión de "guerra ritualizada" que excluye en gran medida a las mujeres. A diferencia de los deportes feminizados, en determinados deportes masculinizados se van a encarnar "los valores de la conquista y de la fuerza" que es precisamente donde se encuentra la lógica de la codificación ritual. Sentencia que los hombres en estos contextos son el colectivo que parece estar encargado de manifestar lo sagrado (2014: 83-103).

En este caso, se podría entender como el futbol base funciona en cierta medida como un ritual contemporáneo, como espacio de sociabilidad de las clases medias, entendidas estas en un sentido genérico y amplio, quienes veneran y reconocen la performance de masculinidad que se da en un espacio sacralizado (el terreno de juego) donde emerge la communitas turneriana efímeramente, sin distinción expresa de clase, con elementos como la obediencia a la autoridad, la uniformización, e incluso la violencia, etc., que ponen de relieve la lógica ritual moderna del fútbol, ya no solo el base, sino incluso el balompié como deporte espectacularizado del capitalismo global actual (Sanfélix 2016).

En el mencionado ejemplo, además, se pueden observar otras características interesantes: el nivel de impregnación del fútbol en lo social, su reconocimiento, su legitimidad, lo que se podría concebir como la futbicuidad (Sanfélix 2016), que lo convierten en unos de los espacios de ritualización de la masculinidad más importantes en gran parte de los países europeos, latinoamericanos y casi ya a escala global. En cierta medida, el futbol es una religión civil que crea divinidades, como tan de manifiesto ha puesto la reciente muerte de Diego Armando Maradona. 
No obstante, se localizan a través de los discursos masculinos (y posteriores observaciones socioantropológicas), otras prácticas que por su particularidad pueden tener mucho que ver con la ritualización de la masculinidad y trascienden claramente espacios institucionalizados como el mundo del fútbol de clubes (base o profesionales).

Aunque en cierta medida pasa como con los quintos, es decir, que las chicas se van incorporando a espacios que se concebían como de (re)producción de la masculinidad, de creación de los hombres de la comunidad, han existido y todavía existen lugares sociales donde los chicos (a finales de la infancia o en la adolescencia -siempre con el grupo de iguales como institución reguladora y promotora de la práctica-) exhiben su masculinidad frente a iguales o ajenas, estas últimas en muchos casos potencial objeto de deseo del "guerrero" que quiere cobrar su recompensa en cuanto vuelva al orden normal de las cosas después de su respectiva batalla o hazaña.

En primer lugar, se han podido recuperar relatos sobre una práctica concreta que en algunas comarcas valencianas se ha venido a denominar "fer harca", que aunque no tiene una traducción clarificadora del valenciano al castellano, simplemente hace referencia a las situaciones en que dos grupos de chicos se desafían para lanzarse piedras los unos contra los otros en un espacio limítrofe que simbólicamente han significado; ríos que separan pueblos, calles que separan barrios, etc.

Algunos de los elementos más destacables dentro de estas lógicas, serían, por ejemplo, la cuestión del secreto, es decir, son prácticas no reveladas al entorno familiar, sino que se dan entre iguales de manera secreta, pese a que puedan ser delatados por el vecindario o alguna herida en la "batalla". Otra cuestión importante, dentro de esta lógica bélica, defensora del territorio, es la camaradería, la cohesión, la generación de identidad grupal, siempre masculina, que en cierto modo lo convierte también en una especie de communitas, quizás alargada en el tiempo (periodo infanto-adolescente) aunque breve e intensa en la experiencia estricta de masculinidad guerrera.

Si bien no existe probablemente nunca una práctica de masculinidad exclusiva que valide para siempre la hombría del candidato, existen prácticas repetitivas y complementarias que van dando al sujeto su estatuto de virilidad reconocida por los iguales y el entorno. En este caso, participar de la batalla, esa donde nuevamente se sacraliza el espacio fronterizo simbólico que separa de los otros (paradójicamente iguales en términos de masculinidad y inevitablemente necesarios para la performance), son puntos que se suman a una especie de 
carnet de virilidad. Se trata del acceso a la fratría, acceso que necesita de la validación de algo que supera a lo individual; es la lógica de la masculinidad tradicional reproducida y engranada mediante en el grupo de iguales (Sanfélix 2019). Aquí van a aparecer ciertos elementos místicos, de solemnidad, sacralidad, etc.

Las otras dos prácticas a las que se hacía referencia, serían las performance de masculinidad en espacios acuático-lúdicos del riesgo (Sanfélix 2017; Sanfélix y Téllez 2017), riesgo creado y asumido para demostrar la valentía exigida y presupuesta a la masculinidad. Básicamente consiste en lanzarse desde cierta altitud a una laguna, acequia, río o similar. Práctica que suele estar protagonizada por grupos de adolescentes y en muchas ocasiones frente a la mirada atenta, o no tanto, de las otras. De nuevo la valentía, la habilidad, la destreza, pero también, lo grupal, la camaradería, la cohesión y ciertas dosis de riesgo, dolor y violencia auto-inflingida van a estar presentes en la validación de una masculinidad demostrada y que en caso de participar de manera activa de la prueba ritualizada, probablemente va a generar episodios de cierto éxtasis grupal en el autoreconocimiento de una masculinidad provisionalmente reconocida y alcanzada.

En segundo lugar, algunos relatos generados en las entrevistas biográficas con hombres del levante peninsular, facilitaron la emergencia de determinadas narraciones sobre situaciones urbanas o en del mundo del ocio nocturno juvenil, básicamente, enfrentamientos entre tribus urbanas y violencia en los entornos de las discotecas, que sin duda también tienen mucho de ritual.

Gran parte de las lógicas de las "tribus urbanas", si es que stricto sensu se pueden denominar así a determinados estilos de vida centrados en lo estético-musical de ciertos jóvenes (formas de subcultura bien digeridas por la hegemonía social), tienen un componente tanto de ritualización como de masculinidad evidente. La violencia que emerge en determinados escenarios de lo social y que todavía hoy es fácilmente localizable en determinados paisajes sociourbanos, es una muestra más de la necesidad de la demostración de una masculinidad inexorablemente asociada a la fuerza, a la dominación y con ello a la violencia.

En definitiva, se puede concluir este apartado, destacando como más allá de la formalización ritual festiva de los quintos, aparecen formas ritualizadas que despliegan el espacio de posibilidad en lo social para la exhibición de los valores asociados a un modelo de masculinidad que, pese a parecer anacrónico, no obstante sigue siendo exigido, o al menos así lo piensan y por tanto actúan los actores sociales que se sienten interpelados. En esta línea es importante destacar cómo con la falta de ritos facilitados por el estado o la comunidad, la propia 
sociedad civil, algunas de estas prácticas ritualizadas van a ser creadas instintiva y casi inconscientemente ad hoc por los propios chicos, quienes sienten una necesidad de demostrar algo que perciben como exigido y que todavía perdura asociado a valores poco funcionales para la sociedad actual.

Algunas de estas prácticas podrían asociarse a la sugerente idea turneriana que clarifica Martine Segalen (2014: 5); se trata de fenómenos de naturaleza "liminoide" (Turner 1974), estructuras que de alguna manera rechazan puntualmente el orden social e incluso la división de clases y que podrían ejemplificarse con determinados fenómenos musicales de masas que tienen cierta similitud con la communitas. Los chicos que saltan desde lo alto de una roca a una laguna de poca profundidad, lo hacen rodeados de iguales y sobre todo como consecuencia de los mandatos de la masculinidad, afrontando esa presión del grupo para demostrar la hombría en un escenario que puede ir cargado de cierta solemnidad, sacralidad, etc., por los silencios, las tensiones, los espacios y la búsqueda de abrazo cálido de lo común.

\section{CONCLUSIONES}

La existencia contrastable empíricamente del nexo entre masculinidad y ritual es un hecho que plantea muchos interrogantes que desde las ciencias sociales deben ser abordados y más en nuestras sociedades contemporáneas. Tanto desde la simple curiosidad científica siempre potencialmente explicativa, como desde una interpretación adecuada de las dinámicas sociales que pueden tejerse en relación con ambos aspectos en breve lapso de tiempo.

En el artículo presentado se han pretendido demostrar estos vínculos, tanto desde un punto de vista de espacios de ritualización de la masculinidad en contextos festivos con los quintos, como mediante otras prácticas ritualizadas con diferentes niveles de institucionalización que aun así tienen un efecto sobre la realidad.

Como se ha tratado de mostrar, diversos autores y autoras, especialmente en el campo de la antropología pero también en otros y desde diferente enfoques, abordan la cuestión del ritual desde su necesidad, su significación o su estructura, pero lo que sin duda prevalece es la idea de que el ritual tiene un impacto sobre la realidad social $y$ que aun viviendo en sociedades industrializadas aparentemente desacralizadas y alejadas de lógicas rituales que articulen los procesos vitales, sin embargo se encuentran formas sociales que más o menos 
directamente se pueden emparentar todavía con lo ritual. Quizás lo ritual tenga hoy más vigencia de lo que se piensa aunque no se sea consciente.

En el caso de la masculinidad esto resulta más que evidente, dada la exigencia construida socialmente y localizada transculturalmente de complementar de alguna manera un sustrato biológico que nunca es suficiente; el hombre se construye a través de dispositivos culturales mediante los cuales demuestra su hombría. Los ritos de paso van a ser un elemento central en esta lógica que tiene efectos casi mágicos sobre el reconocimiento social de una identidad forjada por el patriarcado que a día de hoy y paradójicamente parece ser poco funcional.

En otros términos, la creación de los hombres desde lo cultural con mecanismos con un fuerte componente simbólico, emocional y casi mágico en su acción performativa, da cuenta de la importancia y la casi sacralización de ambas cuestiones: la masculinidad, es decir, la forma aceptada de ser varón en un lugar y tiempo sociohistórico concreto, y el ritual, entendido este como engranaje social mediante el cual se generan personalidades o cohesiones sociales más integradas e intensas desde lo sacralizado y lo solemne. Es el reconocimiento de lo social como razón última que supera al individuo asilado de la sociedad contemporánea. O la autenticidad de la experiencia humana.

Esta última lectura, peque quizás de una visión idealizada del ritual o puede desprender cierta añoranza bucólica de un pasado que nunca existió, puesto que si lo leemos desde una versión durkheimiana, más que libertad individual e incluso colectiva en la aceptación de lo social, existía una casi determinación de lo social en sociedades de solidaridad mecánica que daban poco espacio para las divergencias y el cambio social.

Desde otro punto de vista, en esta perceptible búsqueda de la construcción de sociedades, siguiendo con el francés, de solidaridad orgánica que sean capaces de generar identidades, cohesiones y consciencias compartidas, funcionales y que faciliten la ansiada armonía social del funcionalismo, no obstante se encuentran procesos de individuación y rupturas más o menos claras con el poder del ritual y de lo simbólico que dejan al individuo aislado y puede que en cierta medida desubicado en el espacio-tiempo social propio de su biografía en tiempos actuales.

Pero, con todo esto, ¿son necesarios los rituales o ciertas formas ritualizadas como las del pasado? ¿Nos valen esas formas quizás menos ortodoxas en su pureza pero igualmente rituales de las sociedades contemporáneas? ¿A qué paradojas se enfrenta la sociedad en todo este complejo entramado que liga libertad, individualidad, cohesión e identidad? 
Se ha procurado demostrar como el ámbito festivo es un lugar característico de las sociedades contemporáneas donde el pasado permanece y recobra fuerza y sentido a través del ritual, aunque sea con readaptaciones contemporáneas. Más bien, se relee el pasado y se adapta a un contexto simbólico-ritual y festivo donde se busca esa lógica identitaria, idiosincrática de los pueblos, de las comunidades, de los grupos humanos.

Sin embargo, más allá de particularidades y ritualizaciones, ya para el caso concreto de la masculinidad, los quintos (que parecen ser destacables en el orden festivo ibérico), cobran una fuerza especial, fundamentalmente en determinados ámbitos poblacionales y no necesariamente desde una lectura innovadora o rupturista, sino más bien reproductora y continuista de una masculinidad que para mucha gente y en el contexto social de la eclosión de los feminismos no parece tener razón de ser.

En definitiva, la sociedad española contemporánea se encuentra con diferentes realidades que atañen a muchas variables en los procesos de modernizaciónindividuación, pero que en relación con la identidad masculina continúan proveyendo el espacio de posibilidad para la escenificación de performances de masculinidad que resaltan, legitiman y veneran una hombría tradicional e incluso en ciertos aspectos tóxica que además no es capaz de llegar a la mayoría de población masculina en edad de transición a la supuesta adultez, que en este caso siempre va acompañada de la lógica diferencial de género.

Por eso emergen otras prácticas ritualizadas más allá de lo festivo-comunitario, por eso se revisten de modernidad ciertas dinámicas urbanas o lúdicas que no dejan de glorificar valores clásicos de la hombría. Todo ello, además, en un contexto donde los hombres no parecen tener muy claro su papel en la sociedad, moviéndose entre la aceptación de la institucionalización de las reivindicaciones feministas, la perplejidad acomodaticia e inhabilitante del desnortado o la reacción posmachista agresiva que es potenciada por determinados discursos sociopolíticos vigentes (Sanfélix 2018; 2020).

Así pues, esos mismos discursos pueden ser capaces de apropiarse de las lógicas rituales para dar sentido de pertenencia, de unidad, de cohesión, de darles un norte a los desnortados a través de mecanismos con tanta implicación emocional como un rito de paso, sobre todo si son capaces de dotarlo de toda la parafernalia simbólica que en su momento y a su manera ya ritualizaron los fascismos. Es necesario advertir sobre estas cuestiones, puesto que quienes apelan a determinados pasados en los que lo ritual, lo simbólico, lo estético, lo espacial, jugaron un papel fundamental para una masculinidad bélica y ansiosa de poder, 
no dudarán en recuperar la estrategia en un contexto de necesidad de seguridades ontológicas como el actual, especialmente para el hombre blanco occidental resquebrajado en sus esencias históricas.

Pero y... ¿qué pasa si el (neo)fascismo es capaz de leer la potencialidad de los rituales de masculinidad? ¿Y si son capaces de apropiarse de festividades y ritualizaciones como las de los quintos reconvirtiéndolas en sentido fascista?

Parece evidente que hay cierta necesidad de lo común, de lo colectivo, de acompañamientos grupales que den sentido a las biografías humanas, marcadores cronosociales que ritualizados comunalmente de una u otra manera den sentido de identidad, de pertenencia, de realidad.

No debería tratarse tanto de recobrar viejos rituales o reproducirlos intensificando sus valores tradicionales, sino repensar la lógica ritual desde lo común ofreciendo espacios de posibilidad para los acompañamientos sociales, para los aprendizajes y reconocimientos colectivos. Si no, probablemente solo queda una individuación vertiginosa o una vuelta a pasados oscuros que no parecen ahora tan lejanos.

\section{BIBLIOGRAFÍA}

BADINTER, E. (1993): XY, la identidad masculina, Madrid, Alianza.

BOURDIEU, P. (2007): La dominación masculina, Barcelona, Anagrama.

BOURDIEU, P. (2008): El sentido práctico, Madrid, Siglo XXI de España Editores.

CALVO BRIOSO, B. (2012): Mascaradas de Castilla y León. Tiempo de Fiesta, Consejería de Cultura y Turismo Junta de Castilla y León. Consulta 14 de diciembre de 2020 http://www.jcyl.es/jcyl/patrimoniocultural/mascaradas/fichas/mascaradas.pdf

CANTERO, P. (2003): "Hombrear. Modos de aprender a ser hombre", en Hombres. La construcción cultural de las masculinidades, Madrid, Talasa Ediciones, pp. 5365.

CONNELL, R. (1995): Masculinities, Berkeley \& Los Angeles, CA, University of California Press.

CÓRDOVA, R. (2003): "El concepto de habitus de Pierre Bourdieu y su aplicación a los estudios de género”, Colección Pedagógica Universitaria, 40, pp. 1-10. 
CORNEJO, M. y PIRES, E. (2003): "Una fiesta y varias fronteras: los Quintos de Barrancos (Portugal) y Noblejas (España)", Revista de Antropología Social, 12, pp. 181-198.

DELGADO, L.S. (2019): "Locus de género: Masculinidades y espacios urbanos en contextos de cambio”, Asparkía Investigació Feminista, 35, pp. 45-65.

ESPADA, J.M y CORNEJO, M. (2001): “El Domingo Gordo. La fiesta de los Quintos de Noblejas", Encanal, 7, pp. 5-9.

FERNÁNDEZ-LLEBREZ, F. (2004): “¿Hombres de verdad? Estereotipo masculino, relaciones entre los géneros y ciudadanía”, Foro interno: Anuario de teoría política, 4, pp. 15-44.

GILMORE, D. (1990): Manhood in the making: Cultural concepts of masculinity, New Haven \& London, Yale University Press.

GODELIER, M. (2005): La producción de Grandes hombres. Poder y dominación masculina entre los Baruya de Nueva Guinea, Madrid, Ediciones Akal.

GUTIÉRREZ, A. (2004): "Poder, habitus y representaciones: Recorrido por el concepto de violencia simbólica en Pierre Bourdieu", Revista Complutense de Educación, 15 (1), pp. 289-300.

GUTMANN, M. (1997): “Trafficking in men: The anthropology of masculinity", Annual Review of Anthropology, 26, pp. 385-409.

HERDT, G.H. (1982): Rituals of Manhood: Male initiation in Papua New Guinea, Berkeley, University of California Press.

HERDT, G.H. (1987): Guardians of the flutes: Idioms of masculinity, New York, Columbia University Press.

IDÁÑEZ DE AGUILAR, A.F. (2010): "La fiesta de quintos. Un antiguo ritual de Bienservida”, Al-Basit, Revista de Estudios Albacetenses, 55, pp. 307-328.

MARTÍN, S. (2007): “Los estudios de la masculinidad” en Cuerpo e identidad, Barcelona, Edicions UAB, pp. 89-116.

MEAD, M. (2014): Sexo y temperamento en tres sociedades primitivas, Barcelona, Ediciones Paidós Ibérica.

MORANT, M. (2014): “Cómo llegar a ser hombre con un collar de naranjas y una manta en la cabeza. Análisis de un rito de paso: los naranjeros en "les dances del Rei moro d'Agost"”, Revista de Antropología Experimental, 14, pp. 443-455. DOI: http://dx.doi.org/10.17561/rae.v0i14 
MOSSE, G. (2000): La imagen del hombre. La creación de la moderna masculinidad, Madrid, Talasa Ediciones.

SANFÉLIX, J. (2016): “Fútbol y masculinidad en perspectiva socioantropológica”, en Perspectivas interdisciplinares en el estudio de la cultura y la sociedad, Elche, Universidad Miguel Hernández de Elche, pp. 239-258.

SANFÉLIX, J. (2017) “Demostrando ser hombres. Una aproximación socioantropológica a la construcción y reproducción de las identidades masculinas en las comarcas orientales de la provincia de Valencia", Tesis Doctoral, Departamento/Instituto de Ciencias Sociales y Humanas, Universidad Miguel Hernández de Elche.

SANFÉLIX, J. (2018): "El cuerpo masculino en tiempos de brújulas rotas y (neo)fascismos: análisis socioantropológico", Revista Nuevas Tendencias en Antropología, 9, pp. 15-33.

SANFÉLIX, J. (2019): "La mirada del igual: el grupo masculino como eje articulador, validador y reproductor de la masculinidad tradicional”, en Deconstruyendo la masculinidad. Cultura, género e identidad, Valencia, Tirant Humanidades, pp.165-196.

SANFÉLIX, J. (2020): La brújula rota de la masculinidad, Valencia, Tirant Humanidades.

SANFÉLIX, J. y TÉLLEZ, A. (2014): "Historias de hombres. Recuperando las voces de los hombres reales”, Prisma Social: Revista de Investigación Social, 13, pp. 370406.

SANFÉLIX, J. y TÉLLEZ, A. (2017): "Lógicas Prácticas en el Proceso de Construcción de la Masculinidad de los Hombres Valencianos: Calle, Riesgo, Fútbol y Arca”, Masculinities and Social Change, 6 (2), pp. 96-118. DOI: http://dx.doi.org/10.17583/mcs.2017.1937

SEGALEN, M. (2014): Ritos y rituales contemporáneos, Madrid, Alianza Editorial.

SEGATO, R.L. (2003): Las estructuras elementales de la violencia. Ensayos sobre género entre la antropología, el psicoanálisis y los derechos humanos, Buenos aires, Universidad Nacional de Quilmes.

SUBIRATS, M. (2013): Forjar un hombre, moldear una mujer, Barcelona, Editorial Aresta.

TALAVAN, P. (1989): "El Valle del Ambroz. Ritos de amor y muerte: Los quintos", en Antropología cultural en Extremadura, Mérida, Editora Regional de Extremadura, pp.359-365. 
TURNER, V. (1974): "Liminal to Liminoid, in Play, Flow, and Ritual: An Essay in Comparative Symbology", Rice Institute Pamphlet - Rice University Studies, 60 (3), pp. 53-92. http://hdl.handle.net/1911/63159

TURNER, V. (1991): The ritual process: Structure and anti-structure, Ithaca, NY, Cornell University Press.

VAN GENNEP, A. (2013): Los ritos de paso, Madrid, Alianza Editorial.

VENDRELL, J. (2002): "La masculinidad en cuestión: Reflexiones desde la antropología”, Nueva Antropología. Revista de Ciencias Sociales, 61, pp. 31-52.

Recibido: 14 de diciembre de 2020 Aceptado: 6 de mayo de 2021

Joan Sanfélix Albelda es sociólogo, Máster en Género y Políticas de Igualdad por la Universitat de València y Doctor en Estudios de Género por la Universidad Miguel Hernández de Elche, con calificación de Excelente Cum laude y Premio Extraordinario de Doctorado. Actualmente es Profesor asociado de Sociología en la UJI de Castelló y miembro del grupo de investigación DESiRES en esta misma universidad. Es profesor colaborador externo en el título de posgrado de Especialista Universitario en Masculinidades, Género e Igualdad de la UMH de Elche, donde también es miembro del Observatorio de las masculinidades. Sus principales líneas de investigación se centran en el ámbito de las masculinidades, el género y la igualdad, siguiendo fundamentalmente un enfoque socioantropológico. Recientemente ha publicado el libro La brújula rota de la masculinidad(Tirant lo Blanch, 2020). jsanfeli@uji.es 